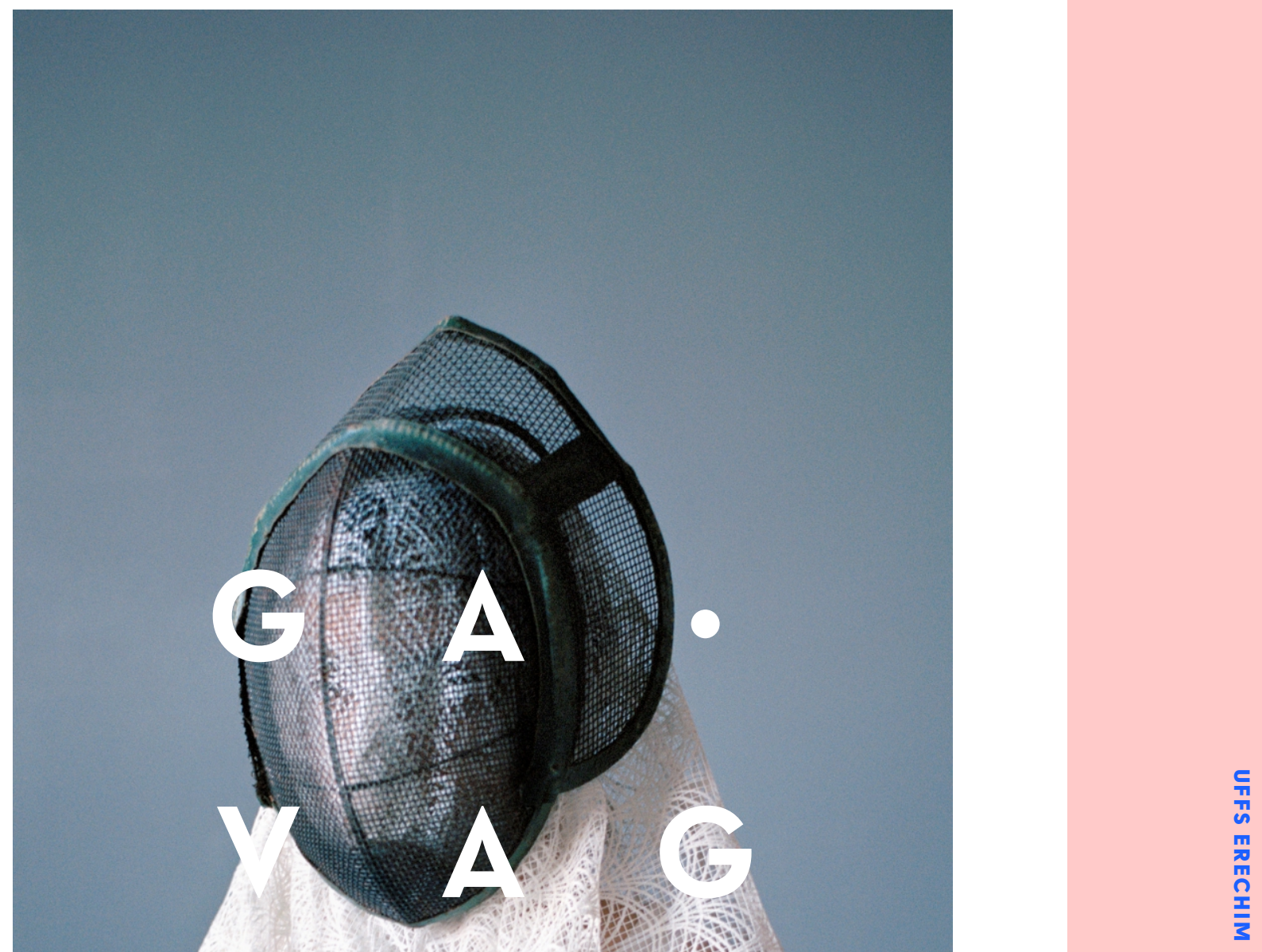


GAVAGAI: REVISTA INTERDISCIPLINAR DE HUMANIDADES

GRUPO DE TRABALHO DO MESTRADO DE CIÊNCIAS HUMANAS

UNIVERSIDADE FEDERAL DA FRONTEIRA SUL, CAMPUS ERECHIM

ENDEREÇO PARA CORRESPONDÊNCIA / DIRECCIÓN POSTAL / MAILING ADDRESS UNIVERSIDADE FEDERAL DA FRONTEIRA SUL, CAMPUS ERECHIM

GAVAGAI - REVISTA INTERDISCIPLINAR DE HUMANIDADES

AV. DOM JOĀO HOFFMANN, 313 ,

BAIRRO FÁTIMA, JUNTO AO SEMINÁRIO NOSSA SENHORA DE FÁTIMA

ERECHIM / RS . CEP 99700.000

FONE: (54) 3321-7050

E-MAIL: GAVAGAI@GAVAGAI.COM.BR

IMAGENS: CAPA / ARTIGOS • SÉRIE HERITAGE • MARIE HUDELOT

ISSN 23580666

DADOS INTERNACIONAIS DE CATALOGAÇĀO NA PUBLICAÇĀO (CIP)

Gavagai: Revista Interdisciplinar de Humanidades/Universidade Federal da Fronteira Sul - Campus Erechim. - Vol. I, n. I (mar./abr. 2014). - Erechim: [s.n.], 2014.

Semestral

1. Periódico. 2. Interdisciplinar. 3. Ciências Humanas.

4. Humanidades. I. Universidade Federal da Fronteira Sul.

Il. Título.

CDD: 300 


$$
\begin{array}{ccc}
\text { - } & \mathbf{G} & \mathbf{A} \\
\mathbf{V} & \bullet & \mathbf{A} \\
\mathbf{G} & \mathbf{A} & \mathbf{I}
\end{array}
$$


EDITOR-CHEFE / EDITOR JEFE / EDITOR-IN-CHIEF

UNIVERSIDADEFEDERAL DESANTA CATARINA (UFSC)

EDITORES EXECUTIVOS / EDITORES EJECUTIVOS / EXECUTIVE

EDITORS

ANI CARLA MARCHESAN

UNIVERSIDADEFEDERAL DAFRONTEIRA SUL, CAMPUS CHAPECÓ (UFFS)

CASSIOBRANCALEONE

UNIVERSIDADEFEDERAL DAFRONTEIRA SUL, CAMPUS ERECHIM (UFFS)

FÁBIO FRANCISCO FELTRIN DE SOUZA

UNIVERSIDADEFEDERAL DA FRONTEIRA SUL, CAMPUS ERECHIM (UFFS)

JERZY ANDRÉ BRZOZOWSKI

UNIVERSIDADEFEDERAL DA FRONTEIRA SUL, CAMPUS ERECHIM (UFFS)

ROBERTO CARLOS RIBEIRO

UNIVERSIDADEFEDERAL DAFRONTEIRA SUL, CAMPUS ERECHIM（UFFS）

ROBERTORAFAEL DIAS DA SILVA

UNIVERSIDADEFEDERAL DAFRONTEIRA SUL, CAMPUS ERECHIM (UFFS) 


\section{CONSELHO EDITORIAL}

- armando chaguaceda - uniVersidad VERACRUZANa (MÉXICO) - BIANCA SALAZAR GUIZZO

. UNIVERSIDADE LUTERANA DO BRASIL (ULBRA) CARLA SOARES - PONTIFICIA UNIVERSIDADE CATÓlICA (PUC-RJ) DANIELA MARZOLA FIALHO - UNIVERSIDAdE FEDERAL DO RIO GRANDE DO SUL (UFRGS) • DÉCIO RIGATTI - UNIVERSIDADE FEDERAL DO RIO GRANDE DO SUL (UFRGS)/ UNIRITTER - DURVAL MUNIZ ALBUQUERQUE JUNIOR - UNIVERSIDAde FEDERALO RIO GRANDE DO NORTE (UFRN). ELIANA DE BARROS MONTEIRO - UNIVERSIDADE FEDERAL DO VALE DO SÃO FRANCISCO (UNIVASF) - ELIO TRUSIAN - UNIVERSITÀ DEGLI STUDI DI ROMA LA SAPIENZA (ITÁLIA) - FÁBIO LUIS LOPES DA SILVA - UNIVERSIDADE FEDERAL DE SANTA CATARINA (UFSC) - FELIPE S. KARASEK - INSTITUTO de DESENVOLVIMENTO CULTURAL (IDC) •

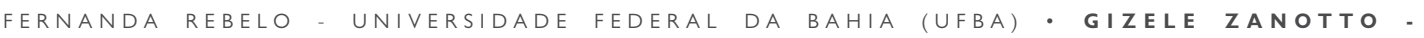
UNIVERSIDADE DE PASSO FUNDO (UPF) • JOSÉ ALVES DE FREITAS NETO - UNIVERSIDADE DE CAMPINAS (UNICAMP) - KANAVILLIL RAJAGOPALAN - UNIVERSIDADE DE CAMPINAS (UNICAMP) - MARGARETH RAGO - UNIVERSIDADE DE CAMPINAS (UNICAMP) - MARIA ANTONIA DE SOUZA - UNIVERSIDADE ESTADUAL DE PONTA GROSSA (UEPG)/ UNIVERSIDADE TUIUTI DO PARANÁ (UTP) - MARIA BERNADETE RAMOS FLORES - UNIVERSIDADE FEDERAL DE SANTA CATARINA

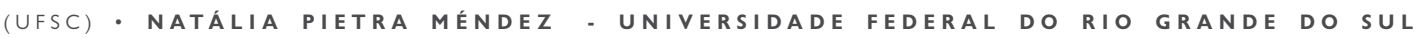
(UFRGS) - NELSON G. GOMES - UNIVERSIDADE DE bRASÍlIA (UNB) - PATRíCIA gRACIELA DA ROCHA - UNIVERSIDADE FEDERAL DO MATO GROSSO DO SUL (UFMS) - PATRICIA MOURA PINHO - UNIVERSIDADE FEDERAL DO PAMPA (UNIPAMPA) - PAULA CORREA HENNING UNIVERSIDADE FEDERAL DO RIO GRANDE (FURG) P PEDRO DE SOUZA - UNIVERSIDADE FEDERAL DE SANTA CATARINA (UFSC) - RAFAEL JOSÉ DOS SANTOS - UNIVERSIDADE DE CAXIAS DO SUL (UCS) - RAfael werner lopes - instituto de desenvolvimento cultural (IDC) • Raul ANTELO - UNIVERSIDADE FEDERAL DE SANTA CATARINA (UFSC) - RICARDO ANDRÉ MARTINS UNIVERSIDADE ESTADUAL DO CENTRO-OESTE (UNICENTRO) - ROBERTO MACHADO UNIVERSIDADE FEDERAL DO RIO DE JANEIRO (UFRJ) - RODRIGO SANTOS DE OLIVEIRAUNIVERSIDADE FEDERAL DO RIO GRANDE (FURG) • ROSÂNGELA PEDRALL - UNIVERIDADE FEDERAL DE SANTA CATARINA (UFSC) - SUZANA G. ALBORNOZ - UNIVERSIDADE FEDERAL DO RIO GRANDE (FURG) - VIVIANE CASTRO CAMOZZATO - UNIVERIDADE ESTADUAL DO RIO GRANDE DO SUL (UERGS). 


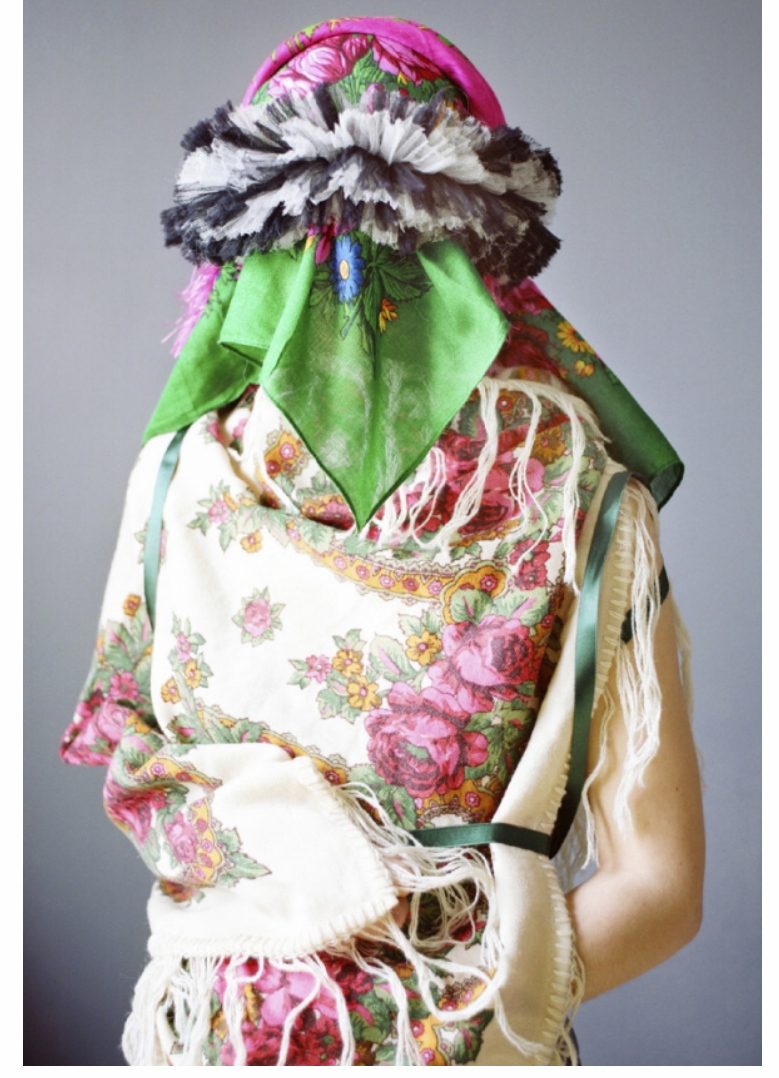

\title{
FOUCAULT E O DIAGNÓSTICO \\ HISTÓRICO-FILOSÓFICO \\ DA MODERNIDADE
}

\begin{abstract}
Resumo: Michel Foucault realizou um diagnóstico da cultura ocidental ao longo de seus ditos e escritos. Esse preceito de subordinar a reflexão filosófica à atividade diagnosticadora se inspira, do ponto de vista programático, na análise nietzschiana da moral. Mas a originalidade das pesquisas foucaultianas consiste em terem incidido basicamente no projeto de repensar os processos históricos, o estatuto do sujeito e a produção da verdade. Daí ser possível assinalar três momentos distintos, porém complementares: na arqueologia, ocorre a denúncia de toda e qualquer "ideologia" humanista; na genealogia dos anos 70, as Ciências do Homem são vinculadas às práticas de normalização dos pensamentos e das condutas; finalmente, nos anos 80, Foucault subordina a Filosofia à tarefa de transfigurar o mundo, o que implica necessariamente em repensar o que entendemos por produção de verdade, prática política e conduta ética.
\end{abstract}

Palavras-chave: Diagnóstico. História. Sujeito. Verdade. 


\section{FILOSOFIA E DIAGNÓSTICO}

Em termos programáticos, Friedrich Nietzsche subordina a atividade filosófica a uma dupla exigência. Por um lado, a desconfiança sistemática em relação a tudo o que até então fora considerado superior, elevado ou de mais alto valor. Deste modo, a própria cultura moderna - através de suas manifestações de ordem artística, moral, religiosa, política, científica e filosófica aparece como resultante de um longo processo de decadência. Por outro lado, Nietzsche leva a filosofia a interagir com domínios até então estrangeiros ou, pelo menos, fronteiriços. Daí a adoção das perspectivas filológica, psicológica, fisiológica, histórica e médica. É nesse sentido que enfatiza o quanto se faz "necessário [além de aplicar a ciência da linguagem aos estudos histórico-morais $]$ [...] transformar a relação entre filosofia, fisiologia e medicina, originalmente tão seca e desconfiada, num intercâmbio dos mais amistosos e frutíferos", ao que se deve adicionar também a "clarificação e interpretação” psicológica (NIETZSCHE, 1988 [1887])!. Tal projeto "interdisciplinar" leva Nietzsche a reivindicar para si a rubrica de "médico da civilização" (NIETZSCHE, 1991 [18721873],\# 175, p. 113).

Essa última imagem - do filósofo que avalia o estado de saúde da cultura - seguramente guarda maior proximidade com as pesquisas arqueogenealógicas de Michel Foucault. Isso fica patente nas entrevistas que se sucedem à publicação de As palavras $e$ as coisas (1966), quando Foucault reiteradamente insiste na ideia que Nietzsche "descobriu que a atividade particular da filosofia consiste no trabalho do diagnóstico: O que somos nós, hoje? Qual é esse 'hoje' no qual vivemos? Tal atividade de diagnóstico comportou um trabalho de escavação sobre seus próprios pés para estabelecer como se constituiu antes dele todo esse universo de pensamento, de discurso, de cultura que era seu universo" (FOUCAULT, 1994a, p. 612).

É preciso salientar, contudo, que, num primeiro momento, o projeto de elaborar um diagnóstico histórico-filosófico da atualidade aparece intimamente relacionado à noção de Estrutura, tendo em vista que ela permite explicitar um acontecimento geral que atravessa a Era Moderna em toda a sua extensão. Através dela,

teóricos, não especialistas, se esforçam em definir relações atuais que podem existir em tal ou qual elemento de nossa cultura, tal ou qual ciência, tal domínio prático ou tal domínio teórico etc. [...] Trata-se de um tipo de estruturalismo generalizado e não mais limitado a um domínio científico preciso [...] que diria respeito [...] a nós, ao nosso mundo atual, ao conjunto de relações práticas ou teóricas que definem nossa modernidade.(FOUCAULT, 1994b, p.581, grifos meus)

Com isso, tal acontecimento pode ser notado em diversos

1 Primeira Dissertação, \# 17, nota. registros: seja no âmago das Ciências do Homem, com a irrupção do conceito de estrutura na psicanálise lacaniana, na etnologia de Lévi-Strauss e na linguística de Saussure; seja na literatura, no caso do primado das "palavras" no nouveau roman francês; seja na oposição entre Ser da Linguagem e Ser do Homem; seja na Lógica Simbólica (de Russel e Wittgenstein), na qual as proposições são convertidas em operações puramente algébricas; seja na obra do matemático Nicolas Bourbaki que, cabe ressaltar, designa "o pseudônimo adotado por um grupo de matemáticos franceses dos anos 1930, cujo objetivo era elaborar livros atualizados sobre todos os ramos da matemática, que pudessem servir de referência para estudantes e pesquisadores" (ROQUE, 2012, p. 428)². O interesse de Foucault nessa coletividade anônima não reside propriamente no conteúdo teórico inovador dela, mas sim na capacidade de tornar ainda mais difusa a noção de autoria.

No entanto, seu intuito não se limita a destacar que a Era do Homem retrata um episódio bem delimitado da história do pensamento ocidental, cujas condições de possibilidade devem ser explicitadas sem recorrer a um referencial antropológico, a uma subjetividade constituinte e, muito menos, a representações sociais. A postura crítica de Foucault para com a modernidade passa, obrigatoriamente, pela tarefa de "diagnosticar o presente, dizer o que é o presente, dizer em que é diferente e absolutamente diferente de tudo o que não é ele, isto é, nosso passado" (FOUCAULT, 1994c, p.665). Ressalte-se que tal conjunção ocorre exclusivamente em entrevistas ou debates e se estende ao longo das três principais fases da obra de Foucault: a "arqueologia do saber", a "genealogia do poder" e a "genealogia da ética".

Essa tendência pode ser verificada logo após o lançamento de Vigiar e punir (1975), quando Foucault defende que seus estudos sobre a prisão têm por objetivo diagnosticar a situação em que nos encontramos a partir do que existe de estratégico e instável nas relações de poder (FOUCAULT, 1994d, p.799). Dois anos depois, e agora tendo como referência as análises de $A$ vontade de saber (1976), Foucault considera a si mesmo um diagnosticador do desejo moderno de decifrar o sexo (FOUCAULT, 1994e, p.261). Em ambos os casos, a atividade filosófica deve estar centrada no "presente" e não na "eternidade": "estamos atravessados por processos, movimentos, forças; não conhecemos esses processos e essas forças, e o papel do filósofo consiste em ser, sem dúvida, o diagnosticador dessas forças, de diagnosticar a atualidade" (FOUCAULT, 1994f, p.573). É nesse sentido que o trabalho histórico-filosófico de Foucault sobre a prisão e a sexualidade, nos anos 70, tem por objetivo dar conta do modo de ser da Modernidade, tanto no que diz respeito a saberes relativos ao homem quanto em relação ao seu aspecto ético-político.

\footnotetext{
2 Sobre a apologia do anonimato através da rubrica Bourbaki, ver Sur les façons d'écrire l'histoire (entrevista a R. Bellour), Dits et écrits, I, p. 597 e Qu'est-ce qu'un auteur? (conferência), Dits et écrits, I, p. 797
} 
A partir de 1980, seus estudos se concentram no período grecoromano. Mas não há propriamente um retorno à antiguidade clássica por dois motivos: em primeiro lugar, no Curso do Colégio de França de 1971 (Lições sobre a vontade de saber) ocorre uma minuciosa leitura das filosofias platônica e aristotélica, além do manifesto interesse na sabedoria de Édipo (que também ocupará lugar de destaque nas conferências $A$ verdade e as formas jurídicas); em segundo lugar, Foucault recorre aos antigos, visando superar a Era Moderna através da constituição de um estilo de existência que permita a "ruptura com as convenções, os hábitos, os valores, da sociedade ocidental" (FOUCAULT, 2009, p.170). Esse anseio por superação, que o próprio Foucault identifica como expressão de uma atitude revolucionária, resulta, pois, da necessidade de avaliar criticamente o modo como somos, pensamos e agimos na atualidade.

A proposta de realizar um diagnóstico histórico-filosófico está ancorada, pelo menos no que diz respeito às suas diretrizes programáticas, a um triplo preceito: deixar de lado o caráter fundante do sujeito; conceber os processos históricos a partir de uma dinâmica "bélica"; subordinar a noção de verdade a elementos políticos e éticos.

\section{A “INVENÇÃO” DO SUJEITO}

O termo invenção designa, numa perspectiva foucaultiana, a inexistência de essências; de ideias, noções ou conceitos préexistentes; em suma, ausência de um ponto de partida ancorado em evidências ou certezas. Também remete a uma concepção descontinuista dos processos históricos, pois desfaz a ilusão retrospectiva de que houve um aprimoramento - linear ou cumulativo - de saberes. Nesse sentido, tanto não é adequado falar em progresso da racionalidade quanto de uma finalidade implícita. Mais ainda, o "método" arqueogenealógico rompe com a ilusão antropológica (e mesmo metafisica) de resgatar unidades ou totalidades ao promover uma historização radical que fragmenta tudo aquilo que se acreditava ser idêntico a si mesmo e envereda pelo campo do múltiplo e da heterogeneidade.

Aplicando essa perspectiva ao caso do sujeito, nos deparamos com a estratégia metodológica de repensar os processos de subjetivação. Daí Foucault ressaltar a importância de "tentar ver como se dá, através da história, a constituição de um sujeito que não é dado definitivamente, que não é aquilo a partir do que a verdade se dá na história, mas de um sujeito que se constitui no interior mesmo da história, e que é a cada instante fundado e refundado na história" (FOUCAULT, 1996 [1974], p.10). Essa perspectiva o leva a afirmar, em Vigiar e punir, que o sujeito não passa de um “átomo fictício" (FOUCAULT, 1975, p.227), o que nos remete diretamente à desconfiança, inaugurada por Nietzsche, em relação aos valores humanistas da Era Moderna, mais exatamente àqueles que colocam o homem na base de tudo o que podemos saber, que o consideram responsável por sua liberdade, que o tornam senhor de sua linguagem, que fazem a história gravitar em torno dele. Porém, o martelo destruidor das verdades eternas não é o mesmo nos dois filósofos de linhagem diagnosticadora.

Enquanto Nietzsche, por exemplo, constata que "o sentido de toda cultura é amestrar o animal de presa 'homem', reduzi-lo a um animal manso e civilizado, doméstico" (NIETZSCHE, 1988 [1887], \# 11, p.40), tolhendo seu potencial criador e afirmador; para Foucault, seria mais apropriado falar de tecnologias que têm por meta aumentar a eficiência dos indivíduos, distribuindo-os em espaços bem delimitados, cronometrando suas atividades, fazendoos evoluir através de exercícios que maximizam suas forças.

Em sua "genealogia da 'alma' moderna” (FOUCAULT, 1975, p.38), ressalta que o julgamento dos delinquentes se faz a partir do que permanece na "sombra" e não do ato propriamente dito. Com isso, "punem-se as agressões, mas, através delas, as agressividades; as violações, mas, ao mesmo tempo, as perversões; os homicídios, que são, também, os impulsos e os desejos" (FOUCAULT, 1975, p.25), ou seja, o que há de mais profundo na mente humana. O diagnóstico foucaultiano - inspirado na tese nietzschiana de que houve uma interiorização dos impulsos espontâneos dos indivíduos pela ação repressora do Estado e/ou da Religião - nos mostra que a prisão reforça uma "tecnologia" altamente eficaz sobre os corpos, cujos principais efeitos são "uma 'alma' a conhecer e uma sujeição a manter” (FOUCAULT, 1975, p.345).

Porém, essa dinâmica não fica restrita ao universo do criminoso, pois se encontra disseminada por toda a sociedade: da sala de aula aos consultórios, passando pelo ambiente de trabalho e pelo treinamento militar. Verificamos semelhante mecanismo entrar insidiosamente em ação também quando surgem discursos normatizadores, notadamente no campo pedagógico e "psi", que impelem os indivíduos a assumirem identidades sexuais - a histérica, o perverso, o masturbador, o casal reprodutor, o homossexual etc. A fabricação de sujeitos é a forma quase que despercebida pela qual o poder se manifesta na modernidade, pois “à medida que o poder se torna mais anônimo e mais funcional, aqueles sobre os quais ele se exerce tendem a ser mais fortemente individualizados" (FOUCAULT, 1975, p.226).

\section{POR UMA COMPREENSÃO GENEALÓGICA DOS PROCESSOS HISTÓRICOS}

No ensaio "Nietzsche, a genealogia, a história" (1971), Foucault considera que o discurso histórico deve recusar a pesquisa metafísica da origem, o que o leva a lhe atribuir as funções de: 1. "inquieta[r] o que se percebia imóvel, fragmenta[r] o que se 
pensava unido, mostra[r] a heterogeneidade do que se imaginava conforme a si mesmo"; 2. explicitar os "diversos sistemas de sujeição", o "jogo casual de dominações” (FOUCAULT, 1994g, p.142-143). Em A verdade e as formas jurídicas, dois anos depois, volta a manifestar sua insatisfação para com a tradição Metafísica ao defender que os processos históricos envolvem rupturas e invariavelmente revelam "algo que possui um pequeno começo, baixo, mesquinho, inconfessável" (FOUCAULT, 1996 [1974], p.15). Através da ideia de "baixas origens", Foucault denuncia a concepção idealista de que existe um estado "anterior a tudo o que é externo, acidental, sucessivo", que se situa "antes da queda, antes do corpo, antes do mundo e do tempo", retratando, por isso, um momento imaculado, perfeito, superior (FOUCAULT, 1994g, p.139) ${ }^{3}$. Do ponto vista genealógico, o devir encontra-se regido por uma combinação de forças atuantes a cada momento que "não obedecem nem a uma destinação, nem a uma mecânica, mas ao acaso da luta” (FOUCAULT, 1994g, p.148).

A leitura de Nietzsche serve de referência para Foucault abordar a reconstituição histórica dos saberes a partir de uma perspectiva de base não-metafísica, na qual o projeto de busca de uma origem ideal é deixado de lado. Cabe destacar ainda que a tarefa de remontar ao passado implica a utilização de um instrumental teórico capaz de dar conta dos mecanismos políticos atuantes no momento presente, isto é, na atualidade. Ao se falar de um diagnóstico da modernidade, contudo, devemos evitar transposições diretas entre a história genealógica de Foucault e a Genealogia da moral do filósofo alemão. Daí ser importante ressaltar que o projeto foucaultiano se caracteriza por realizar uma "genealogia do atual complexo científico-judiciário” (FOUCAULT, 1975, p.30). Isso o leva a se interessar por

uma multiplicidade de processos sempre menores, de origem diferente, de localização esparsa, que se recortam, se repetem ou se imitam, se apóiam uns sobre os outros, se distinguem segundo seu domínio de aplicação, entram em convergência e desenham, pouco a pouco, o esquema de um método geral. (FOUCAULT, 1994g, p.162-163)

A constituição do dispositivo disciplinar, em relação a uma tecnologia do poder de punir - e confessional, no caso da necessidade de extrair uma verdade sobre a sexualidade do indivíduo - , obedece a uma diretriz genealógica não somente porque reconhece que lida com pergaminhos "desordenados, apagados, reescritos” (FOUCAULT, 1994g, p.136), mas também porque coloca em cena relações de força ao mesmo tempo

\footnotetext{
3 É preciso duvidar, adverte Nietzsche (2000 [1876], \# 1, p. 15), de que haja "para as coisas de mais alto valor uma origem miraculosa, diretamente do âmago e da essência da 'coisa em si' " (Humano, demasiado humano, "Das coisas primeiras e últimas").

4 Este livro, aliás, fornece os mais diversos subsídios teóricos: desde as bases morais do nascimento do indivíduo (História da loucura) até o estabelecimento de um modelo de escrita da história (Vigiar e punir e $A$ vontade de saber), passando, é claro, pela crítica do sujeito e pela instauração de um espaço filológico-filosófico (As palavras e as coisas).
}

desequilibradas, heterogêneas, instáveis e tensas. É nesse sentido que a atividade filosófica em Foucault adquire uma função diagnosticadora.

Em oposição ao projeto humanista de tomar o "sujeito como origem e fundamento do Saber, da Liberdade, da Linguagem, e da História” (FOUCAULT, 1994h, p.788), de nele situar, enfim, sua própria verdade; as análises empreendidas por Foucault caracterizam-se pela tentativa de confrontar o homem, sua consciência, sua racionalidade, com aquilo que ao invés de o conduzir tranquilamente ao abrigo do que lhe é familiar, o torna personagem de uma história na qual ele só pode reconhecer os contornos de sua imagem por um breve instante.

\section{POLÍTICA DA VERDADE CORAGEM DA VERDADE}

No início da década de 70, na aula inaugural do Colégio de França - A ordem do discurso - lemos que os discursos (num sentido abrangente) não circulam ou proliferam de modo livre e espontâneo nas sociedades ocidentais: eles são regidos por um conjunto de mecanismos de controle, delimitação e ordenamento. O período arqueológico estava norteado pelo princípio metodológico de que não importa quem fala, ou seja, há uma dissociação entre "conhecimento" e "sujeito". Agora, sem prejuízo dessa perspectiva anti-humanista, verificamos a sobreposição de outro preceito: para entender o alcance de uma fala verdadeira faz-se necessário situá-la em relação a modalidades de governo de si mesmo (fator ético) e dos outros (fator político).

Além disso, a adoção de um referencial genealógico também impele Foucault a "renunciar a toda uma tradição que permite imaginar que só pode haver saber onde as relações de poder estão suspensas e que o saber só pode se desenvolver fora de suas injunções, de suas exigências e de seus interesses" (FOUCAULT, 1975, p.36). Para além de uma concepção tradicional do par saber-poder, que remonta a Platão e que encontra em Nietzsche seu principal adversário, devemos reconhecer que não há heterogeneidade entre a esfera política e a esfera do saber. É nesse sentido que "se quisermos realmente conhecer o conhecimento, saber o que ele é, aprendê-lo em sua raiz, em sua fabricação, devemos nos aproximar não dos filósofos, mas dos políticos, devemos compreender quais são as relações de luta e de poder" (1996 [1974], p.23).

A partir dessa concepção bélica de conhecimento, o genealogista estrutura seu diagnóstico da sociedade disciplinar que se consolida no século XX. Mas não se trata de supor uma gradação: quanto mais saber mais poder. As análises de Foucault retratam uma pressuposição recíproca ou a uma espécie de reforço mútuo 
entre Política e Verdade. Isso fica patente no modo como articula o funcionamento de instituições corretivas, militares, médicas, escolares e industriais, tendo em vista que o ritmo da marcha da tropa e a habilidade no manejo das armas, por exemplo, envolvem não apenas controle e obediência, mas também uma distribuição rigorosa do tempo e do espaço que tem como correlato a eficácia produtiva nas fábricas, a complexidade crescente das tarefas nas instituições de ensino e o planejamento arquitetônico de hospitais e prisões no sentido de tanto limitar a circulação das pessoas quanto favorecer os mecanismos de fiscalização e ordenação das massas humanas.

A concepção foucaultiana de corpo ilustra bem como se dá a junção dos dispositivos de poder com a produção de conhecimentos: existe "um saber do corpo que não é exatamente a ciência de seu funcionamento, e um domínio de suas forças que é mais do que a capacidade de vencê-las: esse saber e esse domínio constituem aquilo que poderemos chamar de tecnologia política do corpo" (FOUCAULT, 1975, p.31). O que Foucault pretende ressaltar é que, do ponto de vista genealógico, seria pobre e insuficiente conceber um "poder que só teria a potência do 'não'; fora do estado de nada produzir, apto somente a colocar limites, seria somente antienergia; tal seria o paradoxo de sua eficácia: nada poder, senão fazer com que aquele que ele submete nada possa fazer, senão o que ele lhe deixa fazer" (FOUCAULT, 1976, p.112). Tal poder opressor certamente existe (Vigiar e punir inclusive o associa explicitamente aos regimes monárquicos), só que o poder estudado por Foucault tem uma positividade, ou seja, uma eficácia política (minimizar o potencial de revolta), econômica (aumento da força de trabalho) e epistemológica (surgimento das Ciências do Homem).

O diagnóstico do presente explica a produção de um saber sobre o homem em termos de uma "política da verdade", pois "o discurso é uma arma de poder, de controle, de assujeitamento, de qualificação e desqualificação [...]" (FOUCAULT, 1994i, p.124). Com isso, o conhecimento adquire uma feição mundana, isto é, deixa de remeter a um estado ideal de pureza e passa a fazer parte de relações de força modificáveis, historicamente datadas e institucionalmente localizáveis. Diagnosticar os efeitos produtivos do binômio saber-poder permite assinalar até que ponto, por exemplo, educadores, agentes de saúde (mental e física), trabalhadores sociais, de modo geral, podem se constituir numa espécie de "funcionários" da ortopedia mental. Esse tipo de indagação retrata justamente a postura crítica da genealogia foucaultiana em relação à modernidade, ou ainda, àquilo que nos tornamos a partir do momento em que as relações sociais passam a ser envolvidas por uma rede de micro-poderes que atuam diariamente sobre os corpos e se respaldam no que se pode saber a respeito tanto de seu funcionamento quanto de sua capacidade de perpetuar os efeitos da máquina produtiva capitalista.
No entanto, se se pretende abranger o campo genealógico percorrido por Foucault em sua máxima extensão, faz-se necessário nos situarmos para além do estudo dos mecanismos normalizadores que perpassam os discursos sobre o indivíduo. É preciso também levar em conta as análises histórico-filosóficas a respeito da problematização da conduta individual, ou seja, o eixo ético das reflexões foucaultianas no qual temáticas como "bom uso da liberdade", "vida como uma obra de arte", "estética da existência", "cuidado de si e dos outros", "arte de governar", tornam-se a matriz a partir da qual o conceito de verdade adquire uma imagem renovada, pois deixa de remeter aos parâmetros lógico-epistemológicos tradicionais.

Ao relacionar o termo grego parresia aos riscos de uma fala verdadeira, Foucault pretende investigar "a questão da importância de dizer a verdade, de saber quem está habilitado para dizer a verdade e por que deveríamos dizer a verdade" (FOUCAULT, 2001, p.170, [“Notas de conclusão"]). Tem-se aqui o primeiro passo no sentido de "construir uma genealogia da atitude crítica da filosofia ocidental" (FOUCAULT, 2001, p.170-171), entendida como a análise de um tipo de discurso capaz de modificar o próprio modo de ser do indivíduo e daqueles que com ele interagem. Logo no início do curso A coragem da verdade, Foucault afirma que pretende "retornar a certo número de problemas contemporâneos" (FOUCAULT, 2009, p.3). Estabelece, com isso, uma ponte entre a fala atrevida da antiguidade greco-romana e o que modernamente vivenciamos na militância revolucionária e na transgressão artística. Seu interesse reside em conjugar a questão do diagnóstico da cultura a uma perspectiva emancipatória, tendo em vista que a conduta parresiástica envolve necessariamente algum tipo de incômodo ou mesmo provocação.

\section{CONCLUSÃO}

As análises arqueogenealógicas de Foucault tanto pretendem determinar como se deu a formação do conceito de homem na modernidade como também realizam um diagnóstico nietzschiano das Ciências do Homem. Estão ancoradas, pois, em obras como O nascimento da tragédia e Assim falou Zaratustra, que despontam, respectivamente, o Nietzsche-médico e o Nietzsche-legislador, ou seja, o filósofo que pretende restaurar o estado de saúde da civilização através da adoção de uma nova tábua de valores. Nos dois casos, a modernidade é diagnosticada como decadente, sendo o humanismo a expressão recente desse movimento cultural.

A dimensão judicativa das pesquisas foucaultianas envolvem questionamentos que, em vez de vislumbrarem o espaço idílico das essências ou o tempo imóvel das ideias, despertam para a tarefa verdadeiramente crítica do diagnóstico do presente. Assim, 
as novas perguntas que se impõem são do tipo: É possível pensar sem se remeter à presença de uma consciência soberana e unitária, fundamento de todo discurso que se pretenda rigoroso? É possível tornar-se agente da história sem invocar um sujeito autônomo, responsável por seu próprio destino e até mesmo pelos rumos da civilização? É possível fazer um bom uso da liberdade para falar e agir de modo coerente e sem receio dos riscos iminentes? Na quarta capa da edição francesa de $\mathrm{O}$ uso dos prazeres e $\mathrm{O}$ cuidado de si, Foucault ilustra o que talvez seja o leitmotiv de seu diagnóstico da cultura ocidental com uma frase do poeta René Char: "A história dos homens é a longa sucessão de sinônimos de um mesmo vocábulo. Contradizê-la é um dever" (FOUCAULT, 2009, p. 212) . Além de destruir evidências, o filósofo-médico instiga o desconforto em relação àquilo que se mostra estagnado.

\section{REFÊRENCIAS}

FOUCAULT, Michel.Le courage de la vérité. Le gouvernement de soi et des autres, II (Cours au Collège de France: 1984). Edição organizada por Frédéric Gros. Paris: Gallimard-Seuil, 2009.

Fearless speech. Editado por Joseph Pearson. Los Angeles: Semiotext(e), 2001.

Dits et écrits (1954-1988). Volumes I, II e III. Paris: Gallimard, 1994.

Qui êtes-vous, professeur Foucault? [entrevista a P. Caruso]. In: FOUCAULT, M. Dits et écrits, tome I, (1954-1969). Paris: Gallimard, 1994a. p.601-620.

La philosophie structuraliste permet de diagnostiquer ce qu'est "aujourd'hui” [entrevista a G. Fellous]. In: FOUCAULT, M. Dits et écrits, tome I, (1954-1969). Paris: Gallimard, 1994b. p.580-585.

. Foucault répond à Sartre [entrevista com J.-P. Elkabbach]. In: FOUCAULT, M. Dits et écrits, tome I, (1954-1969). Paris: Gallimard, 1994c. p.662-668.

. Radioscopie de Michel Foucault [entrevista a J. Chancel] . In: FOUCAULT, M. Dits et écrits, tome II, (1970-1975). Paris: Gallimard, 1994d. p.783-802.

Non au sexe roi [entrevista a B.-H. Lévy]. In: FOUCAULT, M. Dits et écrits, tome III (1976-1979). Paris: Gallimard, 1994e. p.256-269.

. La scène de la philosophie [entrevista a M. Watanabe]. In: FOUCAULT, M. Dits et écrits, tome III (1976-1979). Paris: Gallimard, 1994f. p.571-595.

Nietzsche, la généalogie, l'histoire. In: FOUCAULT, M. Dits et écrits, tome II, (1954-1969). Paris: Gallimard, 1994g. p.136-156.

. La naissance d'un monde [entrevista a J.-M. Palmier]. In: FOUCAULT, M. Dits et écrits, tome I, (1954-1969). Paris: Gallimard, 1994h. p.786-789.

\footnotetext{
5 Nota 33. Esse adendo é de autoria de Daniel Defert.
} 
. Le discours ne doit pas être pris comme... [manuscrito datilografado]. In: FOUCAULT, M. Dits et écrits, tome III (1976-1979). Paris: Gallimard, 1994i. p.123-124.

. La volonté da savoir (Histoire de la sexualité, t. I). Paris Gallimard, 1976.

Surveiller et punir. naissance de la prison. Paris: Gallimard, 1975 (Coleção Tel, edição de bolso).

A verdade e as formas jurídicas - conferências de Michel Foucault na PUC-RJ de 21 a 25 de maio de 1973 Tradução de Roberto Machado e Eduardo Jardim. Rio de janeiro: Nau, 1996 [1a impr.: 1974].

GIACÓIA JÚNIOR, Osvaldo. Filosofia como diagnóstico do presente: Foucault, Nietzsche e a genealogia da ética. In: MARIGUELA, Márcio (Org.). Foucault e a destruição das evidências. Piracicaba, SP: Unimep, 1995, p. 81-100.

Filosofia da cultura e escrita da história - notas sobre as relações entre os projetos de uma genealogia da cultura em Foucault e Nietzsche. O que nos faz pensar. Revista de Filosofia da PUC-RJ, Rio de Janeiro, n.3, p. 24-50, set. 1990.

MACHADO, Roberto. Foucault, a ciência e o saber. 3. ed. rev. e ampl. Rio de Janeiro: Jorge Zahar, 2006.

MAHON, Michel. Foucault's nietzschean genealogy: truth, power, and the subject. Albany: State University of New York Press, 1992

NIETZSCHE, Friedrich. Crepúsculo dos ídolos, ou Como se filosofia com o martelo. Tradução, notas e posfácio de Paulo César Souza. São Paulo: Companhia das Letras, 2006 [Die GötzenDämmerung - oder wie man mit dem Hammer philosophiert, 1888].

Genealogia da moral: um escrito polêmico [em adendo a Além do bem e do mal como complemento e ilustração]. 2.ed. Tradução Paulo César de Souza. Rio de Janeiro: Brasiliense, 1988 [Zur Genealogie der Moral: Eine Streitschrift, Dem letztveröffentlichten "Jenseits von Gut und Bose” Ergänzung und Verdeutlichung, 1887].

Além do bem e do mal: prelúdio a uma filosofia do futuro. Tradução, notas e posfácio de Paulo César Souza. São Paulo: Companhia das Letras, 1992. [Jenseits von Gut und Böse: Vorspiel einer Philosophie der Zukunft, 1885-1886].
Humano, demasiado humano: um livro para espíritos livres. Tradução, notas e posfácio de Paulo César de Souza. São Paulo: Companhia das Letras, 2000 [Menschliches, Allzumenschliches; Erster Band: Ein Buch für freie Geister, 1876].

. Le livre du philosophe. Études théorétiques. Tradução, introdução e notas de Angèle Kremer-Marietti. Paris: Flamarion: 1991 [Das Philosophenbuch.Theoretische Studien; 1872-3, 1875].

ROQUE, Tatiana. História da matemática. Uma visão crítica, desfazendo mitos e lendas. Rio de Janeiro: Zahar, 2012. 


\title{
FOUCAULT'S
}

HISTORICAL-PHILOSOPHICAL DIAGNOSIS

\section{ABOUT MODERNITY}

\begin{abstract}
Michel Foucault carried out a diagnosis of the Western culture throughout his sayings and writings. In a programmatic point of view, such precept based on subordination of the philosophical reflection towards a diagnostic activity has its roots in Nietzsche's analysis of morality. Nevertheless, the novelty in Foucault's studies consists in focusing primarily on the project of rethinking historical processes, the status of the subject and the production of truth. Hence it's possible to point out three distinguishable instants, yet complementary: in archeology, complaint of any humanist "ideology" occurs; in the 1970s genealogy, Human Sciences are bound to the practice of standardization of thoughts and behaviors; and finally, in the 1980s, Foucault entrusts to philosophy with the task of transfiguring the world, which necessarily implies rethinking what we understand by the production of the truth, political practice and ethical conduct.
\end{abstract}

Keywords: Diagnosis. History. Subject. Truth.

\section{FOUCAULT Y EL DIAGNÓSTICO HISTÓRICO-FILOSÓFICO DE LA MODERNIDAD}

Resumen: Michel Foucault realizó un diagnóstico de la cultura occidental en todo sus dichos y escritos. Este precepto de subordinar la reflexión filosófica hacia la actividad diagnosticadora se basa, desde un punto de vista programático, en el análisis de la moralidad nietzscheana. Sin embargo, la originalidad de las investigaciones foucaultianas consiste en centrarse principalmente en el proyecto de repensar los procesos históricos, el estatuto del sujeto y la producción de la verdad. Por lo tanto, es posible señalar tres momentos distintos, aunque complementarios: en la arqueología, se produce la denuncia de la "ideología" humanista; en la genealogía de los años 70, las Ciencias del Hombre están vinculadas a las prácticas de la normalización de los pensamientos y comportamientos; por último, en los años 80, Foucault sostiene que la tarea de la filosofía es transfigurar el mundo, lo que necesariamente implica repensar lo que se entiende por la producción de la verdad, la práctica política y la conducta ética. 


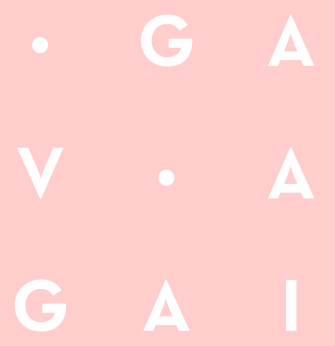

